\title{
Cinema: imagem e interpretação
}

\author{
PAULO ROBERTO ARRUDADE MENEZES
}

\begin{abstract}
RESUMO: Este artigo discute as possibilidades de interpretação das imagens do cinema a partir de suas relações com as artimanhas da ilusão da fotografia na representificação de coisas e pessoas. O cinema nos propõe imagens que articulam de maneira diferencial vários tempos e vários espaços, o que remete, a uma relação com o passado e com a memória que se distingue de sua percepção como uma mera sucessão de eventos. Pelo contrário, a memória articulada pelo cinema nos mostra uma recuperação dos eventos do passado dentro de um fluxo temporal comandado pelo presente e que submete este passado a uma constante resignificação.
\end{abstract}

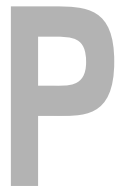

ara investigarmos os caminhos pelos quais as imagens do cinema podem nos levar devemos, inicialmente, dar conta de uma ordem de problemas. As possibilidades para que uma relação cinematográfica aconteça baseiam-se na capacidade fundamental que as imagens fotográficas têm de nos propor um determinado tipo de ilusão. Investiguemos mais de perto este processo e seus pressupostos.

O primeiro deles, diz respeito aos termos em que se coloca a relação entre imagem e objeto e, conseqüentemente, entre fatos ou pessoas que retrata.

Quando vemos a fotografia de um lugar, partimos do pressuposto imediato de que se olhamos para a imagem de uma paisagem, de uma cidade ou de uma casa, isto só pode ocorrer em virtude de que aquele lugar existe, ou existiu, e somente por essa razão pôde se colocar como objeto de fotografia, pôde ser fotografado para que agora nossos olhos ali o vislumbrem e o reconheçam.

É evidente que esse pressuposto não leva em conta o fato de que as imagens, como qualquer outra linguagem, são passíveis de serem adulteradas
UNITERIMIOS: cinema, tempo, espaço, memória, passado, presente, significação.

Professor do Departamento de Sociologia da FFLCH-USP 
Para estas e muitas outras imagens, consulte o instigante e divertido livro de Alain Jaubert (1986), onde o autor nos apresenta as mais variadas maneiras de se reinventar as imagens. ou montadas, podendo, portanto, enganar ou mentir. Como não lembrar da famosa foto da revolução russa que, nos anos de Stalin, teve um de seus integrantes e chefe da guarda vermelha, Trotski, retirado da imagem e, conseqüentemente, da história, como a testemunhar a veracidade do reescrever dos fatos que nos mostrou A revolução dos bichos de George Orwell (cf. 1975). Em outras imagens vemos o "bando dos quatro" desaparecer das fotos oficiais nas quais aparecia ao lado do comandante Mao, nas comemorações da revolução chinesa; ou então vemos o líder da revolução albanesa, Enver Hoxha, que teve sua foto oficial "trabalhada" para esconder a sua proeminente barriguinha, e para "fechar" a sua camisa que saía desleixadamente aberta para fora da calça na imagem original ${ }^{1}$.

O curioso é que, por mais que possamos ter em conta essa perspectiva de simulação e engano, sempre temos a tendência quase natural de acreditar nas imagens que contemplamos antes de que algo nos induza a desconfiar de sua veracidade.

Quando olhamos uma fotografia de uma pessoa esta relação explicita-se. Não é incomum as pessoas carregarem em suas carteiras fotos da esposa, marido ou filhos. Também não é incomum que elas nos sejam mostradas acompanhadas da seguinte frase: "Esta é a minha esposa", ou filha, ou etc. Esta forma de se dirigir à foto deixa claro a transposição que ali está se fazendo entre o que vemos como imagem e a identidade de uma pessoa que não está lá, e que podemos ou não conhecer. Esta transposição vai ocorrer independentemente da qualidade gráfica da reprodução que nos é mostrada, mesmo que a foto seja em preto e branco, esteja desbotada ou envelhecida. Isto, no limite, não importa.

A "verdade" das imagens não está baseada nas características minuciosas com que reproduz objetos ou pessoas, nos detalhes que contempla ou nos defeitos que dissimula. Sua capacidade de iludir, de apresentar uma coisa pela outra, pois é disso que se trata, deve ser procurada em outro lugar. Uma fotografia surge, assim, sempre como a re-presentificação de coisas e, principalmente, de pessoas. Ela nos coloca de novo em presença de. E, não podemos esquecer que esta possibilidade só existe justamente pelo fato de que aquilo que lá está retratado, enquanto imagem, tem que estar obrigatoriamente distante ou no espaço, ou no tempo. Mesmo no caso limite, em que com uma polaroid acabamos de fazer o retrato que estamos agora olhando, aquilo que ali se materializa como imagem engendra em si mesmo uma certa passeidade, um certo deslocamento temporal em relação às novas possíveis visadas de seu modelo.

Se a pessoa nos é desconhecida, passamos a vê-la com uma intimidade a um só tempo, curiosa e ambígua. A familiaridade com a imagem que nos é mostrada faz com que sintamos uma estranha familiaridade com a pessoa que ali está e que passamos a olhar como se já conhecêssemos há muito tempo. Por isso, quando nos perguntam se conhecemos alguém, às vezes dizemos que sim, que conhecemos de vista ou por fotografia. Entidade 
MENEZES, Paulo Roberto Arruda de. Cinema: imagem e interpretação. Tempo Social; Rev. Sociol. USP, S. Paulo, 8(2): 83-104, outubro de 1996.

misteriosa que faz nos sentirmos perto de alguém que nunca vimos ou termos familiaridade com lugares onde nunca passamos.

Para que possamos escapar dessa ambigüidade fundamental devemos olhar para a gênese do processo de constituição das imagens e não apenas para o seu resultado. Por qual razão nenhum pintor, por mais "realista" que pretenda ser, carrega a mesma dose de "realidade" em suas telas que a pior das fotografias consegue facilmente carregar? Por qual razão que ao olharmos para um quadro, como as naturezas-mortas holandeses de Willem Kalf, nossa expressão de espanto será mais naturalmente acompanhada por um "parece uma fotografia", do que acompanhada pela busca de sua semelhança com os objetos que lhe serviram de modelo?

No caso da fotografia, entre o homem e o objeto a ser reproduzido existe somente uma máquina, um aparelho onde a presença do homem pode ser ignorada. Não é por acaso, portanto, que as lentes das máquinas fotográficas foram batizadas com o nome de objetivas, ao propiciar a possibilidade de uma reprodução dos seres e das coisas sem que a mão do homem esteja obrigatoriamente no caminho. Apesar de sempre estarem. Neste sentido, os fundamentos da ilusão baseiam-se na existência de uma reprodução mecânica que exclui o homem, ao menos aparentemente, ao menos na cabeça de quem olha. Esta existência especial, portanto, vai permitir finalmente a transposição da realidade da coisa para a objetividade da realidade da representação.

Pela primeira vez o homem conseguiu construir o duplo perfeito. Mas, curiosamente, não pela precisão e detalhamento das imagens que conseguiu fazer, mas através de uma afinidade psicológica, onde a possibilidade da ilusão da identidade está fundada não mais na semelhança mas exatamente na exclusão, do homem e do tempo (cf. Bazin, 1985, p. 9-17) ${ }^{2}$. E é isto que separa a imagem de alguém de seu sósia. A imagem pressupõe, mesmo que falsamente, a presença passada. A relação de ilusão com o sósia baseia-se em um engano atual, na colocação de um no lugar do outro, ambos estando no presente.

Isto implica que se a fotografia por um lado petrifica o tempo, ou produz um "instantâneo", como por vezes é chamada, por outro nada mais faz do que ressaltar pela pseudo-presença deste mesmo tempo, os indícios de sua ausência. Ao paralisar o tempo, o que ela nos mostra é justamente que o tempo não pára, que ele flui incessantemente sem que contra isto tenhamos qualquer remédio, sem que nunca possamos estancar o seu eterno desdobrar.

O cinema, por sua vez, coloca-se como um meio peculiar para a investigação. Sua análise vai partir obrigatoriamente da percepção de uma duplicidade original. Qual seria o nosso material fundamental de investigação? O filme, a resposta é por demais óbvia. Mas, ao pegarmos o filme em nossas mãos, o que teremos de verdade para submetermos à nossa curiosidade investigativa? Rolos de filme. É evidente que não é esse o material que nos interessa mas, ao contrário, apenas este material em movimento. É a projeção do filme que nos atrai, ou, mais precisamente, o filme em projeção.

\footnotetext{
2 Uma tradução deste texto pode ser encontrada na coletânea organizada por Ismail Xavier (1983, p. 121128).
} 
Em contraposição à idéia de mergulho, (cf. Xavier, 1984, p. 16) nos parece mais apropriado se pensar em imersão, algo que tira o corpo de seu movimento físico e o deixa envolto em outro meio que deverá envolvê-lo como um todo.
Esta ambigüidade inicial, que está presente em toda imagem cinematográfica, colabora para que a ilusão que o cinema herda da fotografia adquira aqui o seu mais alto grau de imaterialidade. $O$ filme está lá sendo projetado e nós que o assistimos podemos nos emocionar. Mas, em nenhum momento ele vai se identificar com os inúmeros rolos de fotogramas em forma bruta que estão escondidos atrás da parede, sendo manipulados por mãos hábeis que fazem sempre a mesma coisa: nos tiram constantemente a percepção de que eles existem. Isto faz com que ver um filme seja uma atividade, em sua origem, diferente daquela que realizamos ao olhar uma fotografia. No cinema nada podemos tocar, nada podemos pegar em nossas mãos, como no caso das fotografias. No cinema alguns de nossos sentidos estão em estado de suspensão. Entramos em um túnel que irá desligar-nos de nossas relações imediatas com o mundo que nos cerca. Quando lá estamos, estamos fora do tempo e do espaço. Estamos em um lugar para entrar em imersão em algo que é absolutamente diferente do mundo do qual saímos e no qual vivemos.

A primeira projeção pública e coletiva, do que então se chamava cinematógrafo, exemplifica muito bem esta relação sui-generis que ora se constituía. Em 28 de dezembro de 1895, os irmãos Lumière alugaram o salão Indiano do Gran Café, em Paris, para projetar dez pequenos filmes de no máximo 3 minutos cada um (cf. Gubern, 1982, p. 30). Eram filmes sem nenhum mistério para os olhos de hoje. A saída de uma fábrica, uma estação de trens, um regimento marchando, um ferreiro a martelar um ferro em brasa, etc. Mas, quem poderia imaginar que durante a projeção da chegada do trem na estação, enquanto a Maria Fumaça se aproximava aumentando de tamanho, o pânico tomaria conta daquelas pessoas que simplesmente saíram correndo com todas as forças que poderiam ter. A sensação de que poderiam ser esmagadas por aquele trem foi inquestionavelmente superior a qualquer raciocínio que poderia lhes ter dito que elas nada sofreriam ao ser atropeladas por fachos de luz e sombras. Assim, o mistério da relação já estava lá presente em todas as suas dimensões. $\mathrm{O}$ articulista de um jornal da época, ao referir-se ao filme que mostrava um ferreiro em ação, exclamava espantado que a cada golpe da marreta o ferro em brasa ficava cada vez mais rubro. O assombro era tão grande que ele chegou a ver cores em um filme totalmente em branco e preto.

Todas as vezes que vamos ao cinema temos que aceitar um certo jogo e nos deixarmos transportar. Quem vai a um cinema e passa o tempo todo dizendo para si mesmo que aquilo é apenas uma combinação de luz e cores, acaba destruindo esta relação de imersão em seus fundamentos e, portanto, simplesmente não deixando nada acontecer ${ }^{3}$. Não há nenhum filme que resista a esta prevenção. A imersão que um filme proporciona deve nos fazer parar de pensar, pelo menos momentaneamente. Não estamos lá para ficarmos raciocinando o tempo todo com o que estamos vendo. Pelo contrário, "é mediante a percepção que podemos compreender a significação do cinema: um filme não é pensado e, sim, percebido" (Merleau-Ponty, 1983, 
MENEZES, Paulo Roberto Arruda de. Cinema: imagem e interpretação. Tempo Social; Rev. Sociol. USP, S. Paulo, 8(2): 83-104, outubro de 1996.

p. 115). Nesse sentido, não é por acaso que os dois elementos essenciais dos filmes são ao mesmo tempo os mais imateriais: a luz e o som. Eles devem penetrar nossos sentidos instantaneamente, sem resguardo, para tomar de uma só vez completamente o espectador, penetrar de uma só vez em seu corpo e em seu espírito.

Aqui se coloca o problema fundamental de quem se debruça para estudo deste meio especial que é o cinema. O que nele devemos olhar? Qual de seus elementos deve ser eleito como o primordial para a análise? Devemos prestar mais atenção no que o filme nos diz ou no como ele nos diz? Como solucionar neste caso a interminável polêmica das artes entre forma e conteúdo? Qual elemento fílmico deve ser essencial para nossas interpretações: as imagens, os sons ou os diálogos? Um filme pode ser o nosso material de investigação ou devermos sempre nos reportar a uma série deles? Qual deve ser a importância dos elementos extra-filmes para sua compreensão? Devemos nos ater mais ao que nos diz o diretor sobre o que quis fazer ou às imagens que ele nos proporcionou? Podem existir diferenças entre essas duas coisas, entre obra e intenção? Conhecer a biografia detalhada do diretor deve ser um elemento chave de interpretação para o que nos parece obscuro em suas obras?

Para que possamos refletir sobre todas essas proposições devemos nos lembrar que o cinema, para se constituir como espetáculo, bebe daquelas mesmas fontes ilusionistas da fotografia. Como a fotografia, ele é também uma arte do espaço. Ou, seria melhor dizer, de uma recomposição do espaço e de espaços. O cinema, portanto, pelo desdobramento espacial que proporciona vai recobrar a temporalidade física que a fotografia havia congelado. Só que, ao mesmo tempo, acaba por alterá-la. O que antes poderia ser confundido com um "tempo real" vai agora aparecer metamorfoseado em um outro tempo radicalmente distinto daquele, mesmo que em alguns casos ele se esforce por confundir-se com ele. Este tempo, de que não nos damos conta e que não é igual, mesmo que dure a mesma coisa, àquele que passou durante a sessão do cinema, é um tempo muito especial, é aquele que nos coloca frente à experiência do tempo, à sua densidade. Aqui acontece, portanto, um deslocamento temporal das imagens que só a imaterialidade da projeção do filme no cinema nos pode proporcionar, e que não se confunde jamais com aquele tempo advindo de sua singela sucessão.

Não é necessário dizer que o que o cinema faz com o espaço encontra similitudes com o que ele faz com o tempo. Tomemos de novo a fotografia como referência. Vimos que ela, ao paralisar o tempo, acaba também por circunscrever e conter um determinado espaço. Este espaço não é, como se poderia primeiramente imaginar, um espaço somente, ou primordialmente, físico.

Marcel Martin autor que parece privilegiar o espaço como o elemento mais importante do cinema. "Elie Faure, num célebre texto intitulado Introduction à la mystique du cinéma escreveu que o cinema 'faz da duração uma dimensão do espaço’. Maurice Schérer, por sua vez, intitulou de 'O cine- 
ma, arte do espaço' um artigo onde afirma que ‘o espaço parece ser a forma geral de sensibilidade que lhe é a mais essencial, na medida em que o cinema é uma arte da visão'. Eis, portanto, dois testemunhos que indicam a primazia do espaço numa definição da especificidade da arte do filme" (Martin, 1990, p. 196). Aqui, ele deixa claro, existe uma subordinação do tempo como dimensão do espaço. Sob um aspecto, ao menos, não restam dúvidas: o cinema é a primeira experiência artística onde um completo domínio do espaço se construiu. Mas, não podemos perder de vista que este espaço é um espaço extremamente peculiar em relação ao espaço da percepção cotidiana das pessoas.

Numa primeira aproximação, podemos dizer que a câmara cinematográfica permite uma representação acrobática do espaço. Quem não se lembra, em Cidadão Kane, da cena onde a câmara vem voando pelo céu para depois entrar por uma clarabóia do telhado, descendo até uma mesa de bar onde está a ex-esposa de Kane, Susy. Não é preciso ressaltar toda a dimensão psicológica que este vôo da objetiva incrusta no espaço meramente físico de um bar qualquer. Vemos aqui a versão em movimento das pinturas futuristas (como A Risada, de Boccioni) que tentavam através de imagens estáticas recuperar não só o movimento das coisas mas, e principalmente, as variações de seus estados de espírito. O estado psicológico dos personagens é, através desse artifício, incorporado como dimensão do próprio espaço construído. Temos aí, portanto, a separação definitiva entre a reconstrução de um espaço meramente físico e a construção de um espaço muito mais complexo, um espaço que passa a não mais responder às leis do olhar e da perspectiva.

O cinema, conseqüentemente, pode tratar o espaço de pelo menos duas formas distintas. Pode ser um mero reprodutor de espacialidades físicas, onde pelo movimento da câmara e pelas longas tomadas (planos-seqüência), tenta-se reproduzir um espaço dado qualquer. Mas, e é aí que o mistério se mostra em sua plenitude, pode também ser o produtor de espaços singulares, percebidos como únicos e contínuos, não por o serem na realidade mas apenas podendo ser vistos como tal por meio da justaposição sucessiva de fragmentos alinhavados caprichosamente pela vontade e arbítrio do montador, ou pelas exigências estéticas do diretor. Dessa maneira, espaços absolutamente descontínuos passam a parecer interligados como se estivessem uns ao lado dos outros. Como não lembrar aqui de $O$ Gabinete do Dr. Caligari ou de $M$ - o vampiro de Düsseldorf. Em ambos os filmes, espaços totalmente descontínuos encontram sua organicidade apenas na mente do espectador, ligados pela ordem dramática que os enseja, por mais ilógicos que eles possam parecer materialmente.

A montagem vai operar este milagre. A sucessão de dois planos consecutivos vai criar entre eles uma continuidade espacial virtual, pois não podemos esquecer jamais que um filme não é o duplo de uma realidade qualquer e que ele sempre se dirige para o imaginário de quem o vê. O imaginário 
MENEZES, Paulo Roberto Arruda de. Cinema: imagem e interpretação. Tempo Social; Rev. Sociol. USP, S. Paulo, 8(2): 83-104, outubro de 1996.

não é aqui entendido como o oposto de um real que se distinguiria dele como a água do óleo. "No sentido corrente da palavra, o imaginário é o domínio da imaginação, compreendida como faculdade criativa, produtora de imagens interiores eventualmente exteriorizáveis. Praticamente sinônimo de 'fictício', de 'inventado' " (Aumont, 1993, p. 118). Pelo contrário, pensamos que imaginário e as imagens das quais se utiliza são uma dimensão do real do qual não podem ser organicamente separados. O imaginário não é um outro que se contraporia ao real como ilusão ou engano, mas uma dimensão necessária da própria percepção que temos de nós mesmos e das coisas.

Paul Virilio nos mostra que o imaginário é o primeiro lugar de todas as batalhas. "A guerra não pode jamais ser separada deste espetáculo mágico porque sua principal finalidade é justamente a produção deste espetáculo: abater o adversário é menos capturá-lo do que cativá-lo, é infligir, antes da morte, o pânico da morte. Para cada episódio decisivo da história das batalhas existe um homem para lembrar, de Maquiavel a Vauban, de von Molkte a Churchil: 'A força das armas não é uma força brutal, mas uma força espiritual'. Não existe, portanto, guerra sem representação ou arma sofisticada sem mistificação psicológica, pois, antes de serem instrumentos de destruição, as armas são instrumentos de percepção [...]" (Virilio, 1993, p. 12). O cinema é, neste contexto, uma criação do imaginário para o imaginário e não, como quer o pensamento singelo, uma reconstrução de uma realidade exterior qualquer. O cinema não fala diretamente do real, não é uma reprodução mais que perfeita deste real, e sim uma construção a partir dele e que dele se distingue. Mas, ao mesmo tempo, ele necessita que a ilusão da representificação esteja sempre presente. É aí que se faz a mágica. $O$ filme faz a interligação entre imaginário e memória através da construção de espaços e da proposição de experiências diferenciais de tempos.

Neste sentido, entendemos esta ilusão não a perda da percepção da separação entre o espectador e o filme, como se ele estivesse dissolvido e se confundindo com as imagens que aprecia, mas uma relação especial que se constitui entre ele e o filme, um jogo que não confunde o filme com o real, como se houvesse uma identificação entre ele e imagem, mas como uma experiência ilusória, no sentido de uma "articulação 'criativa' entre [...] duas ordens de realidade": a interna e a externa (Winnicott citado em Pontalis, 1977, p. 177). Assim, esta forma de ilusão não nos remeteria àquela dos cinemas realistas, em suas várias concepções (cf. Xavier, 1984 e 1988), mas apenas ao fundamento que porta esta ilusão herdada da fotografia, que mesmo um cinema que se propõe não-realista, como o surrealista, utiliza para negar. Quadros como os de Magritte, bem como filmes como $O$ cão andaluz, de Buñuel, constroem o estranhamento das imagens que propõem exatamente em uma articulação diferente da esperada dos atributos do que é costumeiro para nossa visão. É justamente da tentativa de rebater aquelas imagens para algo reconhecível com sentido que a artimanha se constrói e com ela a nossa sensação de algo estranho está lá à nossa vista. Para afirmar, ou para negar, o pressuposto 
MENEZES, Paulo Roberto Arruda de. Cinema: imagem e interpretação. Tempo Social; Rev. Sociol. USP, S. Paulo, 8(2): 83-104, outubro de 1996.

${ }^{4}$ Se podemos imaginar ser a fotografia um tempo recortado, que paralisa um evento em um tempo passado, não podemos por outro lado nos esquecer que ela recobra uma outra temporalidade pelo olhar de hoje que a contempla e que a reinsere em um outro fluxo, o fluxo do tempo do presente de quem a olha. é o mesmo: de que aquilo que está lá existe ou existiu. Ou, no limite, algo que é passível de ser pensado como possível de existir.

Mas, nesse momento, retornamos para o nosso problema original. O filme é primordialmente uma arte do tempo ou do espaço?

Martin parece se render às evidências e por fim confessa: "Pareceme que, ao tomarmos contato com o filme, apesar das aparências realistas e figurativas da imagem, não é o espaço que se impõe a nós desde o início com mais força, e sim o tempo. Seria possível, com efeito, conceber um filme que fosse temporalidade pura, um filme cujas imagens fossem brancas, ou negras, como em L'homme atlantique (Duras), onde as seqüências sem imagens figurativas, deixam perceber apenas o quadro obscuro da tela (experiência semelhante à do famoso quadro de Malevich Quadrado branco sobre fundo branco). Somos portanto, capazes de perceber o tempo do filme (duração vivida), mesmo na ausência do tempo no filme (tempo da ação)" (Martin, 1990, p. 200).

Assim, o espaço físico construído pela câmara é um espaço fílmico, onde o tempo tem uma dominação absoluta. A continuidade de espaços heterogêneos e assimétricos se dá pela justaposição temporal de fatias de tempo que vão determinar sua percepção, como acelerado ou retardado, como contínuo ou interrompido, portanto, como atributos de uma relação que liga esta experiência às nossas próprias experiências subjetivas. É assim que se pode falar que não existe espaço $d o$ filme, mas somente espaço no filme. Se a pintura bem como como a fotografia podem ser pensadas como realizações $d o$ espaço, o cinema só pode ser pensado como uma realização no espaço. Pensamos, neste sentido, o espaço de um filme como puramente fílmico, como uma invenção plástica carregada de atributos psíquicos.

$\mathrm{O}$ que antes era a imagem das coisas passa a ser a imagem da duração das coisas. O cinema reintroduz nas imagens o que a fotografia delas retirou, restaura ofluir de uma temporalidade ${ }^{4}$. Mas esta temporalidade não é nunca, ou quase nunca, a temporalidade do "real". O cinema substitui, portanto, o aparente "foi assim" da fotografia pelo "é assim" da experiência do tempo das coisas.

O cinema é único na criação da ilusão do tempo. É, sem dúvida, o meio que consegue construir a maior aproximação da ilusão do tempo "real", do tempo vivido e, conseqüentemente, da experiência do tempo que todos nós sentimos.

O cinema é, portanto, mais uma composição de tempos do que uma composição no tempo. A estrutura temporal de um filme nada tem a ver com a reprodução de um suposto tempo "real" ou algum tempo do real. O tempo do cinema e o tempo no cinema são um tempo que se vivencia, sendo assim uma experiência de e no tempo. Como nos sugere Tarkovski, o cinema é um estado onde são indissolúveis tempo e memória. $\mathrm{O}$ tempo que se vivencia, $\mathrm{o}$ tempo vivido, é o tempo cravado em nós como experiência, a impressão que temos do tempo, sua intensidade (cf. Tarkovski, 1990, p. 64-68). 
Neste sentido, todo cineasta é um pensador, que pensa através das imagens que constrói. É um construtor de sensações e não de coisas. E, talvez, seja esta uma das razões pelas quais as pessoas vão ao cinema. Vão até lá resgatar vivências que já tiveram ou buscar experiências que não viveram. Em ambos os casos buscam o tempo perdido. O seu tempo perdido.

Os estudos sobre o tempo levam sempre em conta a instauração de uma ambigüidade fundamental, que surge com a instauração do modo de produção capitalista e que o distinguiria dos tempos dos modos de produção pré ou não capitalistas. Do século XIV ao XIX, a transição do Feudalismo ao Capitalismo proporcionou também uma profunda alteração das formas de percepção do tempo e suas influências nas vida das pessoas, da produção à vida cotidiana. $\mathrm{O}$ tempo, até então, era predominantemente cíclico, medido pelas forças da natureza, pela chuva e pelo sol, pela noite e pelo dia. Este tempo era também o tempo instituído pela religiosidade cristã no mundo ocidental. "De fato, a atividade mercantil introduz uma nova forma de temporalidade, distinta daquela instituída pelas práticas cristãs, caracterizadas pela representação da eternidade, pela repetição ritual do sacrifício do filho de Deus, pela idéia de que o tempo pertence a Deus, e o que a ele pertence não pode ser profanado, isto é, não pode ser atribuído um preço e ser vendido. Ora, o empréstimo de dinheiro a juros, a usura, vai introduzir uma radical alteração na consciência do tempo, que de dádiva divina passa a ser objeto lucrativo" (Bruni, 1991, p. 157).

O novo tempo que se instaura deixa de lado todas as qualificações que constituem o tempo cíclico. O tempo passa a ser predominantemente um tempo homogêneo, contínuo, abstrato, linear e independente das intempéries, aspirando apenas a uma única qualidade: ser quantitativamente perfeito para poder ser continuamente repartido e, portanto, transformar-se em um elemento passível de ser controlado e domesticado, a um só tempo dominado e dominador. Este é o tempo do relógio, mas não daquele que levamos no pulso e que é referência de nossas atividades e compromissos e sim daquele outro, cristalizado no relógio de ponto, símbolo eficaz da sua nova capacidade de disciplinar, dominar e vender. Ele se diferencia fundamentalmente daquele seu ancestral, que foi "introduzido primeiro na praça pública para avisar a hora dos ofícios sagrados e as horas da feira e do mercado" (Bruni, 1991, p. 158). Agora ele é um tempo que assume para si mesmo a idéia de continuidade incessante, raiz da idéia fundamental de progresso. Mas, devemos ter em conta que este tempo que se instaura não aniquila os outros tempos sobre os quais se torna preponderante. Ao contrário, sob a aparente homogeneidade do tempo do relógio temos o incessante desdobrar de uma multiplicidade de tempos que o permeiam e que se inserem em sua trama aparentemente contínua.

Da continuidade e do progresso deste tempo se elidem todos os elementos que levariam a perceber que o tempo contínuo é antes de tudo, e essencialmente, uma completa abstração. Não só por ser medido e repartido por convenções como o minuto, a hora, o segundo, mas, principalmente, por 
nivelar a sua passagem em um fluir de ritmo perene que só acontece na realidade do relógio, e mesmo assim somente daqueles que não estão desregulados. "A continuidade assim fabricada não tem, com toda evidência, nenhuma ligação com uma continuidade real; possui, todavia, todos os atributos de uma continuidade real" (Bachelard, 1988, p. 63). Que o tempo passe sempre no mesmo ritmo e na mesma intensidade é uma mentira que qualquer um que já tenha vivido qualquer coisa saberá rapidamente desmentir. Este tempo sempre igual e incessante é, pelo contrário, uma abstração distantemente referencial.

Basta estarmos atrasados para que esta abstração se desfaça. Quando esperamos ansiosos a chegada de um trem de metrô, aqueles 3 minutos de sempre se transformam em um pedaço, nem sempre pequeno, da eternidade. O tempo que passa marcado pelo relógio e a experiência deste mesmo tempo vivida pelas pessoas são coisas completamente diferentes. A sensação que temos da passagem do tempo está ligada diretamente à intensidade dos fenômenos que o preenchem. As sensações de prazer ou desprazer fazem com que a fruição deste tempo varie em relação ao tempo abstrato do relógio. Os amantes apaixonados sempre reclamam da falta de tempo. Aquelas duas horas do encontro fortuito dos amantes escoam por seus dedos com a rapidez de um relâmpago. Por outro lado, as duas horas de tratamento de canal em um dentista nos causam a dor de uma tortura que parece durar milênios. Não vemos a hora em que acabe, pois cada minuto é vivenciado com a lentidão de uma câmara lenta. Este tempo vivido é um tempo subjetivo. "A experiência interior temporal de uma pessoa particular não é mensurável de nenhum modo, ou melhor, não pode ser expressa como a quantidade de tempo transcorrido. Cada um sabe como pode acontecer do tempo 'não passar nunca' ou que passe muito rápido [...]. O tempo vivido é uma função da carga ou da ausência (do vazio) de experiências interiores do sujeito. [...] As horas carregadas de acontecimentos podem ser sentidas como 'extremamente largas' pois nelas aconteceu muita coisa, ou então e pelo mesmo motivo, como 'extremamente breves'. É sobre tudo o conteúdo do acontecimento que estabelece se a experiência interior será 'muito grande' ou 'muito curta' " (Heller, 1977, p. 392-393).

Neste tempo como vivência, nesta experiência diferencial do tempo, aquele tempo do escoamento incessante transforma-se no que ele era desde a sua origem, uma pura e completa abstração. Aparece, nesse contexto, como figura do pensamento que tende a esconder outras dimensões desta malha temporal, essencialmente descontínua, que só encontra seu fluxo linear através de uma convenção. "Dando destaque às funções da memória, das tradições dos rituais coletivos, da repetição, mostram como, de certo modo a cultura pode neutralizar o tempo (esse tempo do escoamento perpétuo), o que determina uma experiência subjetiva do tempo totalmente diferente daquela até aqui examinada, em que o passado ou o presente podem tornar-se a dimensão privilegiada" (Bruni, 1991, p. 161).

No cinema, o tempo e o espaço são os elementos fundamentais. Isto 
MENEZES, Paulo Roberto Arruda de. Cinema: imagem e interpretação. Tempo Social; Rev. Sociol. USP, S. Paulo, 8(2): 83-104, outubro de 1996.

quer dizer que uma análise que se prenda diretamente à história dos filmes, sem conseguir distinguir as formas pelas quais tempos e espaços são construídos e articulados na elaboração daquele mesmo conteúdo, será sempre uma análise fadada a ficar no limiar da compreensão de sentido que a obra deve portar. Se assim não o fosse, para que precisaríamos ir ao cinema. Bastaria ficarmos em casa, sentados em nossa poltrona, lendo confortavelmente o roteiro. $\mathrm{O}$ conteúdo de um filme é muito mais que o conteúdo de um roteiro, por mais perfeito que este seja. Se aqui ele é pura literatura, ali ele vai ser reelaborado por uma outra linguagem, essencialmente mais ambígua e abstrata. São as imagens criadas pelo cineasta que dão às letras mortas de um roteiro a consistência de um conteúdo que vai ser absorvido pela platéia. Esse conteúdo não existe, nem preexiste, às formas que o fazem nascer. E essa é a razão pela qual, um mesmo roteiro, filmado por dos cineastas diferentes podem levar a "conteúdos" bastante diferentes, quando não mesmo antagônicos. Veja-se a obra-prima de Godard, A Bout de Soufle, comparada com a refilmagem americana de Jim MacBride, Breathless. Toda a densidade psicológica do personagem principal do filme francês transforma-se em idiossincrasias e maneirismos através de Richard Gere no filme americano. Esses dois filmes estão muito longe de mostrar o que seria abstratamente visto como o mesmo "conteúdo", partindo ambos de uma mesma "história".

Voltemos a refletir sobre as questões do tempo. Tomemos, inicialmente, suas dimensões materiais.

De saída, o movimento que costumamos associar aos filmes é totalmente ilusório pois nenhuma câmera capta realmente um movimento, um tempo contínuo. Temos, ao contrário, uma sucessão de imagens estáticas que em sua somatória recobram para nós a sensação de movimento pela reintrodução do tempo, de seu tempo. E isto não se deu de maneira fácil ou natural. Quem não se lembra daqueles filmes antigos nos quais os personagens sempre se movem rapidamente, acelerados por uma relação de tempo que contrasta com a que percebemos as coisas. É só a partir da possibilidade de projeção dos filmes em 24 quadros por segundo que a ilusão de que as coisas se movimentam na tela na mesma velocidade que nós as percebemos cotidianamente teve a chance de se realizar.

O que temos lá, por essa sucessão de movimentos e de tempos, é uma abertura para outras dimensões onde o tempo é aparentemente um continuum que nos leva do passado ao futuro.

Martin nos alerta de uma tripla noção do tempo no cinema. A primeira estaria diretamente ligada ao tempo de projeção, à duração da sessão. A segunda, ao tempo da ação que se desenrola, ao tempo da história que se conta. A terceira, ligada diretamente à nossa percepção, à sensação de que o filme passou rápido ou muito devagar (cf. Martin, 1990, p. 214). Sabine Gross parece concordar com esta relação tripartite. Ela apenas elabora de uma maneira um pouco diferente a terceira dessas noções. Ela a chama de "tempo do arranjo da história quanto é mostrado e em qual seqüência” (Gross, 1992, 
p. 20). Se partirmos do pressuposto que é deste arranjo que tiramos nossa vivência no cinema, podemos pressupor que ele é o fundamento de nossa sensação de filme lento ou rápido.

Mas, em que termos colocar-se-ia, então, a questão sobre as relações entre o tempo no filme e um pretenso "tempo" do real?

Já vimos que um filme é uma articulação, ou desarticulação, não importa, mas uma sucessão de espaços que podem ser contínuos, mas que nos mais das vezes são assimétricos e descontínuos, psicológicos e plásticos. Esta sucessão, como também já vimos, é subordinada a uma construção temporal. Não existe nenhuma razão para pressupormos que esse tempo tenha que ser contínuo, apesar dessa ser a sensação que normalmente nos transmitem os filmes que assistimos.

Antes de mais nada, devemos nos lembrar que nos primórdios do cinema não existia o que depois se tornou essencial: a idéia de sincronia. Não existia, como necessidade original, a obrigatoriedade de que fossem as mesmas as velocidades de filmagem e de projeção. Este tempo variava segundo fatores muito estranhos para os dias de hoje. Por exemplo, os donos de cinemas faziam filmes de comprimentos diferentes caberem na duração sempre igual de uma mesma sessão. Assim, filmes mais longos se tornavam obrigatoriamente mais rápidos. Da mesma forma que as sessões noturnas, onde era maior o afluxo de público, eram mais curtas do que as vespertinas, apesar de passarem filmes de igual comprimento. Griffith, o grande diretor americano dos anos 10, recomendava diferentes velocidades de projeção, não só entre os diferentes rolos de um mesmo filme, mas também entre diferentes momentos de um mesmo rolo. Ou seja, não existia nenhuma padronização entre os tempos de um filme. "Parece que a sincronização das velocidades que levaria a uma representação realista do tempo não era nem mesmo considerada necessária e, pelo contrário, uma discrepância que levava a uma representação acelerada ou distorcida do tempo era agradavelmente aceita" (Gross, 1992, p. 14).

A atração inicial das pessoas com os filmes estava centrada não no fato deles serem uma cópia fiel da realidade mas exatamente no fato de não o serem. Eles espantavam muito mais pelo seu detalhamento do que pelo realismo, muito mais por criar um mundo mágico, um desconhecido dentro do reconhecível, do que pela capacidade de duplicar o já visto.

Neste sentido, a sincronia, bem como a continuidade, são frutos de um estratagema original. A ilusão de que o tempo transcorre sem interrupções advém da articulação ininterrupta de tempos paralisados. Afinal, o que é um filme senão uma somatória de fotogramas que passam na frente de uma luz a uma velocidade que, pela inércia do aparelho ótico, liga suas projeções em uma continuidade imaginária realizada apenas em nossa retina. Portanto, a sensação de movimento é criada a partir da sucessão de imagens estáticas que através da sua projeção nos iludem e enganam. Eisenstein levou este estratagema até o limite. Não só cada um dos quadros de seus filmes é uma 
MENEZES, Paulo Roberto Arruda de. Cinema: imagem e interpretação. Tempo Social; Rev. Sociol. USP, S. Paulo, 8(2): 83-104, outubro de 1996.

imagem estática. Ele filmava tomadas inteiras de vários segundos, e até minutos, de objetos parados. Através da montagem ${ }^{5}$, que contrapunha imagens com idéias contrastantes, a história que estava sendo projetada recuperava um ritmo de ação que simplesmente não existia nas tomadas originais. Tomemos, por exemplo, a cena da invasão do Palácio de Inverno em Outubro, que simboliza a derrubada do Czar. A sucessão de tomadas estáticas de uma boca de canhão, dos portões do Palácio e de uma estátua tombada do Czar criaram o "conceito" de queda de um sistema político. Vemos movimento onde, na verdade, não havia nenhum.

Essa correlação entre tempo real e tempo no filme, é totalmente imaginária. Senão, como poderia ter sido realizado um filme como Cidadão Kane, onde uma vida de seis décadas é recontada pelo trabalho de um repórter em uma semana, tudo isto projetado em 118 minutos de filme.

Devemos lembrar também que a reconstrução de tempos e espaços nos filmes sempre se fez através de convenções. Nos filmes antigos, a passagem de uma cena para outra era percebida como visualmente descontínua. Como poderia alguém sair de um quarto e aparecer em uma sala? Para dar conta deste desconforto visual provocado pela quebra de continuidade introduziam-se imagens intermediárias com inter-títulos ou mesmo apenas uma imagem preta para que com isto, ao igualarem-se duas descontinuidades, fosse possível recobrar-se uma continuidade do filme no imaginário. É certo que esta prática hoje em dia seria ele mesma vista como $A$ quebra de continuidade.

As formas tradicionais de se alterar essa percepção do tempo são por demais conhecidas do grande público para aqui nos determos nelas. A imagem acelerada é muito usada em comédias (veja-se os famosos três patetas e os filmes de Chaplin) e em filmes científicos para nos mostrar movimentos lentos demais para serem percebidos a olho nu, como é o caso do crescimento das plantas. Como efeito dramático, sua utilização mais conhecida é, sem dúvida, nos filmes de Godfrey Reggio, Koyaanisqatsi e Powaqqatsi, onde o confronto e o contraste das relações entre homem e natureza nas sociedades contemporâneas expressa-se pela ritmo alucinante das imagens nas sociedades de consumo, dos trens de metrô às compras no supermercado.

A câmara lenta, por sua vez, altera em outra dimensão o efeito dramático das cenas que compõe. Pode nos mostrar coisas que os olhos não seriam capazes de desvelar por si mesmos: a trajetória de um tiro ou de uma flecha, a queda-livre de um corpo no espaço, o movimento das chamas que envolvem algum objeto. Para dar apenas um exemplo extremo, a da transformação da imagem morte em tempo e espaço fílmico, basta lembrar a cena da roleta russa onde morre um dos personagens principais do filme $O$ Franco-atirador de Michel Cimino. Existe ali a dilatação de um momento crucial, no qual a expansão do tempo vai servir como artifício para a intensificação da densidade emotiva do evento. Qual é o tempo real de um tiro de revólver? Alguns milésimos de segundo, sem dúvida. Expandir este tiro,

${ }^{5}$ Para maiores detalhes ver Eisenstein (1983). 
para que a cena se passe em alguns segundos tempo suficiente para nos mostrar a faísca que detona o cartucho, a bala saindo do cano e entrando na cabeça que pula impelida pelo seu impacto, o sangue que esguicha vigorosamente para cima e o corpo que cai finalmente ao chão transforma o que seria o simulacro perfeito do real em uma hiper-realidade totalmente estética. Vemos, na verdade, não o que veríamos cotidianamente mas, pelo contrário, o que justamente nossas vistas não têm a capacidade de acompanhar.

De qualquer jeito, todos parecem concordar que o que é realmente decisivo na reconstrução do tempo propiciada pelo cinema é o seu aspecto subjetivo. "Este é o prolongamento muito especial do opsigne [ou drama ótico]: tornar sensível o tempo, o pensamento, os tornar visíveis e sonoros" (Deleuze, 1985, p. 29).

Este é o aspecto que mais nos interessa. O cinema é mais um meio de evocar histórias do que de contá-las. Tarkovski nos diz que "o fator dominante e todo-poderoso da imagem cinematográfica é o ritmo, que expressa o fluxo do tempo no interior do fotograma" (Tarkovski, 1990, p. 134). Este fluxo deve estar contido em cada fotograma e dele não se separa pois é de sua sucessão que se constrói no filme, e em sua projeção se realiza, uma nova temporalidade que temos a possibilidade de experimentar como se fosse a nossa.

Talvez o exemplo mais drástico esteja em alguns filmes do cinema underground norte-americano, do qual Andy Warhol era um de seus mais interessantes protagonistas. Seu filme $O$ Beijo mostra, durante 109 minutos e em câmara lenta, um beijo ininterrupto entre John Lennon e Yoko Ono. Mas um outro de seus filmes, Sleep, vai levar esta experiência ao extremo. O cenário é extremamente simples: um quarto, com uma cama. O filme começa, a porta se abre, entra um jovem loiro que tira a roupa, deita na cama e dorme. Seis horas depois ele acorda, levanta, e sai pela porta. Fim. Esta é a expressão mais absoluta da colagem de um tempo real com o tempo de um filme. É o maior exemplo, pelo menos o mais comprido, da identidade absoluta entre dois tempos não conciliáveis. E sua conciliação nada mais nos mostra que estes tempos são efetivamente distintos. Tarkovski também gosta de brincar com essa identidade perdida. Algumas das longas cenas de seus filmes são realizadas em tempo real. Em $O$ sacrifício vemos um carteiro atravessar morros e morros de bicicleta, até chegar a uma casa para entregar uma correspondência. Tudo isto leva uns dez minutos. Mas a nossa ansiedade é tão grande que este tempo parece não terminar nunca. Essa forma temporal de ritmo bastante calmo faz com que os filmes de Tarkovski tenham muita dificuldade de ser vistos na América, onde os olhos do grande público já estão mais acostumados com velocidades de cenas mais próximas de videoclipes e fliperamas. O lento saborear foi sendo transformado em intensidade expressiva direta e violenta. Isto mudou muito dos anos 70 até hoje. A velocidade das imagens foi aumentando pois passou-se a consumir imagens com a mesma velocidade com que antes consumia-se sabonetes. A partir do momento que se vive o tempo 
MENEZES, Paulo Roberto Arruda de. Cinema: imagem e interpretação. Tempo Social; Rev. Sociol. USP, S. Paulo, 8(2): 83-104, outubro de 1996.

do consumo, essencialmente rápido e curto pois um produto não foi feito para ter memória, o tempo da degustação, do olhar paciente e cativante que recupera o passado e articula a memória no tempo que se esvai vai sendo deixado de lado.

Por isto Kristeva nos diz, com uma certa desconfiança, que "a arte da imagem prima pela mostra bruta da monstruosidade: o cinema permanece como a arte suprema do apocalíptico, quaisquer que sejam os seus requintes, de tanto que a imagem tem o poder de 'fazer-nos caminhar no medo'... Nessa dicotomia imagem/palavra, cabe ao cinema expor a rudeza do horror ou os esquemas externos do prazer [...]" (Kristeva, p. 203).

Deste fluxo é que brotam a intensidade e a densidade do tempo reconstruído, sua pressão, seu processo vital. "Um filme é uma realidade emocional, e é assim que a platéia o recebe-como uma segunda realidade" (Tarkovski, 1990, p. 211).É por isso que o cinema nos coloca em experiência, nos faz vivenciar situações que de outra maneira seriam impossíveis para nós. Além de que o cinema é o meio especial para mostrar que as palavras, as ações humanas e os estados de espírito não andam em sintonia e, em casos extremos, desmascaram-se mutuamente. Por esta razão o elemento fílmico primordial nunca poderia ser as falas e os diálogos. Daríamos ao cineasta o racionalismo absoluto que não damos a nós mesmos quando falamos. Quem vai ao cinema para ler palavras acaba recusando para si mesmo a imersão primordial que é mãe da experiência que aquele cineasta quer conosco compartilhar. O cinema é primordialmente luzes e sons e são eles que nos proporcionam as emoções mais diretas e sensíveis. Quando um cineasta quer nos assustar, ele não quer que pensemos no susto. Quer simplesmente que nos assustemos, que vivenciássemos esta experiência singular.

Para podermos experimentar o tempo não podemos nos esquecer que o tempo só pode fluir por estar indissoluvelmente ligado ao passado e, portanto, à memória. "Privado da memória, o homem torna-se prisioneiro de uma existência ilusória; ao ficar à margem do tempo, ele é incapaz de compreender os elos que o ligam ao mundo exterior - em outras palavras, vêse condenado à loucura" (Tarkovski, 1990, p. 64). É a existência de um passado que articula nossos tempos em um fluxo que possa ter algum sentido. E é a intensidade do momento presente que busca na memória sempre descontínua do passado o que a ele interessa relembrar naquele contexto peculiar. O nosso passado, rearticulado pela memória, entra no nosso fluxo presente e aí adquire sentido. Nosso passado não é uma linha reta articulada sucessivamente pela memória. Nem a memória traz à tona os eventos passados mantendo burocraticamente sua sucessão no tempo abstrato das datas do calendário. Se, como diz Nietzsche, o pensamento vem quando ele quer e não quando nós queremos (cf. 1971, DPF, \#17), por que com a memória o processo seria diferente. Assim, a possibilidade de lembrar é demandada pelo momento presente que faz surgir e que lhe dá o seu significado. Com isso, e nessa perspectiva, o passado deixa de ser um livro aberto no qual nossa vida está 
escrita de uma maneira definitiva para passar a ser um eterno rememorar, no qual a cada vez os mesmos acontecimentos se inserem em diferentes significações, dependendo do fluxo presente que os articula e demanda.

"Proust também fala da construção de 'um vasto edifício de memórias', e creio ser exatamente esta a função do cinema, que poderíamos definir como a manifestação ideal do conceito japonês de saba" (Tarkovski, 1990, p. 67). Este conceito é explicitado através de uma citação do jornalista soviético Ovchinnikov: "Considera-se que o tempo, per se, ajuda a tornar conhecida a essência das coisas. Os japoneses, portanto, têm um fascínio especial por todos os sinais de velhice. Sentem-se atraídos pelo tom escurecido de uma velha árvore, pela aspereza de uma rocha ou até mesmo pelo aspecto sujo de uma figura cujas extremidades foram manuseadas por um grande número de pessoas. A todos esses sinais de uma idade avançada eles dão o nome de saba, que significa, literalmente, 'corrosão'. Saba, então, é um desgaste natural da matéria, o fascínio da antigüidade, a marca do tempo, ou pátina. Saba, como elemento do belo, corporifica a ligação entre arte e natureza" (Tarkovski, 1990, p. 66).

O cinema não é o duplo perfeito mas sua capacidade de se colocar como se fosse torna clara as formas pelas quais organizamos e orientamos nosso tempo e espaço, já totalmente naturalizados como sendo atributos eternos de nós mesmos. O cinema não é o duplo de qualquer realidade mas ele sempre nos ajuda a olhar para essa mesma realidade. Ele é uma ficção que nos permite uma aproximação maior com essa realidade do que se víssemos o seu duplo reproduzido. Justamente por não ser o real, ele vai nos permitir perceber os tempos e espaços que o compõem, a dissolução de tempos que comporta e a articulação de memórias que engendra.

Se pensamos ser o cinema uma construção de imagens que tem a capacidade de brincar com o tempo, ele vai ter também a capacidade de trabalhar com a memória. Pois o fluir do tempo só é possível de ser pensado como tempo que se escoa, ou que se desdobra, em tempo que vai, e tempo que foi. É impossível nos pensarmos a nós mesmos sem levar em conta nossa inserção em um fluxo de eventos que constituem em seu desenrolar a percepção de nossa identidade e de nosso lugar no mundo. Visto por este prisma, o passado e a memória não são atributos de um já foi eterno, mas, ao contrário, uma necessidade imperiosa de um eterno vir a ser, parte indissociável de nosso próprio presente, que o rearticula, o redimensiona e o (re)significa a cada momento.

Neste contexto, nosso passado nunca será uma enciclopédia cronológica remissiva de nós mesmos, à qual podemos lançar mão para olharmos nossa vida em retrospectiva e em sucessão, mas uma misteriosa obra aberta, no sentido em que Calvino a concebe, um emaranhado de acontecimentos que podem ser lidos em qualquer direção e em qualquer ordem, alinhavados por um imperativo que não é do passado mas sim de um eterno tornar-se presente no presente, que em seu movimento recupera, e ao 
MENEZES, Paulo Roberto Arruda de. Cinema: imagem e interpretação. Tempo Social; Rev. Sociol. USP, S. Paulo, 8(2): 83-104, outubro de 1996.

recuperar reinterpreta, as imagens que naquele momento são para nós significativas e que aí, curiosamente, adquirem também um novo significado, iluminadas a cada vez por um novo desenrolar de acontecimentos.

Nunca vivemos as mesmas coisas. Por isto lembramos de coisas diferentes em um mesmo lugar e das mesmas coisas em lugares diferentes. Por isso o mesmo evento pode surgir com significados diferentes. Da mesma forma, a emersão do passado no presente sempre surge diferente, recontextualizada por uma nova ordenação que ele (o passado) é incapaz de controlar. Nessa perspectiva, seria até impreciso falar que nós possuímos um passado. Possuímos passado, ou então vários passados. Podemos caminhar pela obra que escrevemos de nós mesmos em várias direções diferentes e iluminá-las com várias cores diferentes. Dificilmente daí surgirá um e o mesmo passado.

O cinema pode trabalhar com o passado de formas muito diferentes. Suas formas tradicionais apresentam-se por dois caminhos diferentes. No primeiro deles, temos o desenrolar de uma história que se apresenta em sucessão temporal linear, acompanhando o desdobramento dos acontecimentos na mesma medida em que eles acontecem. Esta sucessão temporal pode expressar algo que acontece em poucas horas (After Hours ou Duro de Matar) ou durante toda uma vida ou vidas (Raízes ou Poderoso Chefão). No segundo, temos uma história que se desenvolve e que em alguns momentos necessita do aparecer do passado para nos explicar ou elucidar algo que por si só não poderia ser compreendido. A técnica tradicional aqui utilizada é o famoso flash back, com suas variantes de esfumaçamento da imagem ou simples recorte para trás (Gabinete do Dr. Caligari ou Forest Gump). Nesta acepção, o passado retorna para o presente como lembrança, como souvenir. Ele é o outro do presente.

Estas formas tradicionais compõem o tempo e o reconstroem seguindo uma linearidade que esconde ser aquela sucessão apenas uma dentre muitas possibilidades. Ela dá ao espectador a confortável segurança de que sua vida se desdobra sempre na mesma direção e sempre sem sobressaltos. Nos interessa aqui, entretanto, caminhar em outra direção. Este outro caminho é com certeza muito mais indefinido e impreciso que o anterior pois porta em seu próprio descobrimento a multiplicação de perspectivas que transformam seu (e nosso) próprio presente e seu próprio passado em entidades problemáticas que carecem ser desvendadas em seus significados mutantes.

Como não lembrar aqui do talvez mais clássico dos filmes que trabalharam o tempo dentro desta perspectiva: Cidadão Kane. Sua construção é exemplar pois mostra ao espectador todos os artifícios que constroem a história de todos nós. Sua história começa com a morte de Kane, que pronuncia a palavra mágica Rosebud e, logo a seguir, com a projeção de um documentário sobre sua vida e seus feitos. Durando algo em torno de 10 minutos, o fim deste desenrolar de fatos que conformaram sua vida nos deixa com a estranha sensação de que passamos a saber tudo sobre ela, ao mesmo tempo que parecemos nada saber, na verdade. Sua última palavra jogará sobre 
a história uma indefinição insuperável. Por ser a última deve ser importante e todas as buscas do repórter vão ser feitas no sentido de tentar recuperar a importância desta nomeação (pois ninguém sabe do que se trata pessoa, evento ou objeto) que, por dever ter um significado essencial, encobre todos as fáceis interpretações que costumam bastar para termos a sensação de que conhecemos e dominamos uma vida qualquer.

Sua busca é curiosa, ao mesmo tempo que fadada ao fracasso. Kane está morto. Portanto a sua própria memória é impossível de ser vasculhada. Mesmo que isso fosse possível, quantas verdades dali não poderiam brotar? Procura ele, então, reconstruir o significado de uma vida através do depoimento de várias das pessoas que com ele conviveram. É aí que os mistérios do passado e da memória vão mostrar-se com toda a sua indeterminação. A cada novo personagem encontrado e entrevistado, uma nova vida se reconstrói. $\mathrm{O}$ que vai deixando o repórter desconcertado é que as novas descobertas sobre Kane nunca se somam às anteriores, como o fazem as peças de um quebracabeças. Ao contrário, parecem subtrair-se o tempo todo pois não se encaixam nos lugares desejados. O resultado de sua busca acaba revelando vários Kanes diferentes, e até mesmo incoerentes entre si, uma multiplicidade a um só tempo inacessível e incompreensível pois a cada dado novo, ao invés de caminharmos para elucidações sucessivas, o que vemos descortinar-se aos nossos olhos é uma quantidade cada vez maior de indefinições contraditórias.

O fetiche do significado final continua a ser a descoberta do significado da palavra mágica Rosebud, mágica pelo seu poder de fazer o homem procurar o inapreensível, mágica por fazê-lo desconfiar do visível, mágica por fazer tudo girar em torno dela sem que ela nada nos diga. E como poderia ter este poder uma palavra. Como poderia apenas uma palavra portar uma resposta que iluminasse sem sombras o significado de toda uma vida? Seu grande poder não está em seu significado intrínseco, mas em ser uma fonte que vai fazer brotar toda uma série de significados possíveis. Temos ali, no fim do filme, a reconstrução de vários Kanes e, ao mesmo tempo, de nenhum. Todos estão lá e o Kane que morreu não é recoberto por nenhum deles. Ele é todos e nenhum ao mesmo tempo. Esta indefinição, ou definições múltiplas se quiserem, permanece para todos os personagens do filme até o fim. Eles morrerão sem saber qual é o significado da palavra mágica, sem saber que ela na verdade nada significa. Somente nós espectadores seremos brindados com o esclarecimento que nada esclarece, ao vermos no forno da cena final, o trenó de sua infância ser devorado pelas chamas, ao mesmo tempo que se ilumina para nós a palavra tão procurada que ele tem impresso em seu assento. Mas, se nada se esclarece sobre a história de uma vida, tudo ilumina sobre os caminhos e descaminhos do passado e do presente, e de suas relações sempre complexas com a memória.

De suas relações com a construção de um presente, que articula diferencialmente pedaços de passado, pedaços de memória, da maneira pela qual se trabalha este tempo que flui, este tempo que é a um só tempo presente 
MENEZES, Paulo Roberto Arruda de. Cinema: imagem e interpretação. Tempo Social; Rev. Sociol. USP, S. Paulo, 8(2): 83-104, outubro de 1996.

e passado, vão brotar várias (pois afinal, o que é esgotável?) possibilidades diferenciais de percepção e incorporação do passado.

Tomamos a distinção entre formas diferentes de se relacionar com o passado, portanto, de se relacionarem tempo e memória. Se nos afastamos da perspectiva ingênua onde o cinema é um mero duplo do real, repetindo em luz e sons os atributos de um real que ele espelha e reproduz, com maior ou menor perfeição, não podemos também adotar a perspectiva tradicional da relação com a memória como forma de reconstruir um passado distante no espaço e no tempo.

Tomemos as imagens de Providence, de Alain Resnais. Aqui não temos mais um passado que retorna como lembrança, como recordação, como outro. Temos, ao contrário, uma evocação do passado no presente, um desdobramento do presente em presente e passado, um ir a ele, uma dissolução da separação que o transformava em coisa distante no tempo. Se, como quer Nietzsche, "não existem fatos, somente interpretações" (1978, 7[60], p. 304305), esta evocação do passado pelo presente, como uma interpretação, "é um meio de se tornar senhor de qualquer coisa" (1978, 2[148], p. 141), é um meio de nos tornarmos senhores de nosso passado, de escaparmos da escravidão que ele exercia sobre nós. O tempo não é mais apenas irreversível. Ele é também irrevogável. O que evocamos não é apenas algo que passou. É, principalmente, algo que fizemos.

A busca da proposição de significados dá-se pela interpretação dos meandros de espaços e de tempos que a imagem cinematográfica engendra e nos mostra. É da análise dessa intrincada composição de tempos e espaços que podemos compreender os valores que estão sendo colocados em questão, não só ressaltando a diferença entre as coisas sobre as quais pensamos, mas também sobre as que fazemos e as que conseguimos ver, que problematizam lugares diferentes de nossa constituição valorativa. Conseguindo perceber não só os valores ligados às coisas mas também os lugares hierárquicos que lhe são reservados por uma certa época e sua cultura, podemos finalmente colocálos em questão e propor, a partir desses lugares diferenciais, a própria reavaliação desses mesmos valores.

Assim, pensar o passado e, conseqüentemente, as relações entre presente e memória, nos dá pistas cruciais para que possamos compreender a articulação das imagens em tempos diferenciados que o cinema nos apresenta, buscando a cada passo novos significados para a percepção do complexo edifício de nossas vidas e de nossa inserção no fluxo interminável da história. Pois, se "a confiança na vida não existe mais; [e] a própria vida torna-se problema" (Nietzsche, 1982, P, \# 3, p. 25), refletir sobre o passado é uma das formas de se tentar continuar pensando sobre o impensável, em um momento em que o afã pelo moderno parece ter transformado o olhar para trás e a reflexão sobre o passado em pura perda de tempo. 
UNITERIMOS:

\section{Cinema,}

time,

space,

memory,

past,

present,

signification.
MENEZES, Paulo Roberto Arruda de. Cinema: image and interpretation. Tempo Social; Rev. Sociol. USP, S. Paulo, 8(2): 83-104, october 1996.

\section{REFERÊNCIASBIBLOGRÁFCAS}

ANDERSON \& Richie. (1982) The japanese film. Princeton, New Jersey, 1982. Bachelard, Gaston. (1988) A dialética da duração. São Paulo, Ed. Ática. BARTHES, Roland. (1984) A câmara clara. Rio de Janeiro, Ed. Nova Fronteira, Bazin, André. (1985) Qu'est-ce que le cinéma? Paris, Ed. du Cerf.

Benjamin, Walter. (1986a) Aimagem de Proust. In: . Obras escolhidas I. São Paulo, Brasiliense. p. 36-49. . (1986b) A obra de arte na era de sua reprodutibilidade técnica. In: . Obras escolhidas I. São Paulo, Brasiliense. p. 165-196.

Bruni, José Carlos (1991) Tempo e trabalho intelectual. Tempo Social, São Paulo, 3(1-2): 155-168.

Deleuze, Gilles. (1985) L’Image-temps. Paris, Éditions de Minuit.

EISENSTEIN, Serguéi M. (1983) Vários. In: XAVIER, Ismail (org.). A experiência do cinema. Rio de Janeiro, Graal. p. 187-243)

Ferro, M. (1970) Cinéma et histoire. Paris, Denöel/Gonthier. . (1984) Film et histoire. Paris, Édition de L'École des Hautes Études en Sciences Sociales.

FREund, Gisele. (1976) La fotografia como documento social. Barcelona, Ed. Gustavo Gili.

Goldmann, Annie. (1985) L'Errance dans le cinéma contemporain. Paris, Henri Veyrier.

Gombrich, E. H. (1986) Arte e ilusão. São Paulo, Martins Fontes.

Gross, Sabine. (1992) Film real time, life time, media time. (mimeo).

Gubern, R. (1982) História del cine. Barcelona, Ed. Lumen.

Heller, Agnés. (1977) Sociologia de la vida cotidiana. Barcelona, Ed. Península. 
Hosokawa, S. (1994) Por um bom viajante nostálgico. Imagens, Campinas, 2: 96-103, agosto.

JANKÉLÉVITCH, V. (1974) L'Irreversible et la nostalgie. Paris, Flammarion.

JAUBERT, Alain (1986) Le Comissariat aux archives - les photos quifalsifient l'Histoire. Paris, Éditions Bernard Barrault.

Kolker, R. P. (1983) The altering eye. New York, Oxford University Press.

Kristeva, Júlia. (1989) Sol negro-depressão e melancolia. Rio de Janeiro, Ed. Rocco.

Martin, Michel. (1990) A linguagem cinematográfica. São Paulo, Ed. Brasiliense.

MARX, K. Textos 3. Ed. Sociais, s/d.

Merleau-Ponty, Maurice. (1983) O cinema e a nova psicologia. In: XAVIER, Ismail (org.). A experiência do cinema. Rio de Janeiro, Graal. p. 103-117.

MoRIn, Edgar. (1985) Le cinéma ou l’homme imaginaire. Paris, Les Éditions du Minuit.

Nietzsche, Friedrich. (1971) Par-delà bien et mal. Textos e variantes organizados por Giorgio Colli e Mazzino Montinari. Trad. De Cornélius Heim. (DPF - Des préjugés des philosophes). Paris, Éditions Gallimard.

. (1978) Fragments posthumes. Automne 1885 - automne 1887. Paris, Gallimard.

. (1982) Le gai savoir. Textos e variantes organizados por Giorgio Colli e Mazzino Montinari. Trad. de Pierre Klossowski. ( $\mathrm{P}$ - préface à la deuxième édition; V - variante). Paris, Éditions Gallimard.

ORwell, George. (1975) A revolução dos bichos. São Paulo, Edibolso.

Pontalis, J. B. (1977) Entre le rêve et la douleur. Paris, Gallimard.

Robinson, D. (1980) Panorama du cinéma mondial. Paris, Denöel/Gonthier.

Simmel, Georg. (1983) Simmel. Coleção Grandes Cientistas Sociais. São Paulo, Ed. Ática.

Sontag, Susan. (1981) Ensaios sobre fotografia. São Paulo, Ed. Arbor.

Sorlin, Pierre. (1977) Sociologie du cinéma. Paris, Aubier.

TARKovski, Andrei. (1990) Esculpir o tempo. São Paulo, Ed. Martins Fontes.

VIRILIO, P. (1993) Guerra e cinema. São Paulo, Ed. Página Aberta.

Vogel, Amos. (1974) Film as a subversive Art. New York, Randon House.

XAVIER, Ismail (org). (1983) A experiência do cinema. Rio de Janeiro, Embrafilme/Graal. 
MENEZES, Paulo Roberto Arruda de. Cinema: imagem e interpretação. Tempo Social; Rev. Sociol. USP, S. Paulo, 8(2):

83-104, outubro de 1996.

(1984) O discurso cinematográfico, a opacidade e a transparência. São Paulo, Ed. Paz e Terra.

. (1988) Cinema: revelação e engano. In: NovaEs, Adauto (org.). $O$ olhar. São Paulo, Companhia das Letras. p. 367-383. 